\title{
Association between oral health-related quality of life and nutritional status among older adults in district of Kuala Pilah, Malaysia
}

\author{
Tanti Irawati Rosli ${ }^{1} 2^{*}$, Yoke Mun Chan ${ }^{3}$, Rahimah Abdul Kadir ${ }^{4}$ and Tengku Aizan Abdul Hamid ${ }^{2}$
}

\begin{abstract}
Background: Poor oral health has an impact on food choices and intake of important nutrients among older population. The use of oral health-related quality of life instruments along with the clinical dental indicators can help to assess the oral problems that lead to nutritional problems in this group. This study aims to determine the association between oral health-related quality of life (OHRQoL) and nutritional status among a group of older adults in Kuala Pilah district, Malaysia.

Methods: A cross-sectional study was carried out on 446 older adults aged 50 years and above from 20 randomly selected villages. Respondents were interviewed to collect information on their demographic characteristics and oral health perception, followed by physical examination to measure height, weight and body mass index (BMI) of respondents. The validated Malay version of General Oral Health Assessment Index (GOHAl) was used to measure OHRQOL.

Results: About one-third (35.8\%) of the respondents had normal BMI. Majority of the respondents were overweight $(40.4 \%)$ and obese (19.9\%), while only a small proportion was underweight (3.9\%). Mean GOHAl score was 53.3 $(S D=4.7)$, indicating low perception of oral health. About $81.6 \%$ respondents had moderate to low perception of oral health. Logistic regression analysis showed a statistically significant association between the GOHAI and BMI scores $(\mathrm{OR}=2.3 ; p<0.01)$.

Conclusions: Oral health-related quality of life was significantly associated with nutritional condition of respondents. Older adults with poor perception of their oral health were more likely to have unsatisfactory BMI compared to those who perceived their oral health to be good.
\end{abstract}

Keywords: Quality of life, GOHAl, BMI, Nutritional status, Elderly

\section{Background}

Like other developing countries, population ageing in Malaysia has become a major issue. It is documented that the proportion of population aged 60 years and above has risen from $6.3 \%$ in 2000 to $7.8 \%$ in 2010 and is expected to reach $10.7 \%$ in 2020 [1]. This phenomenon is a result

\footnotetext{
* Correspondence: tantiir@ukm.edu.my

${ }^{1}$ Department of Dental Public Health, Faculty of Dentistry, Universiti Kebangsaan Malaysia, Jalan Raja Muda Abdul Aziz, 50300 Kuala Lumpur, Wilayah Persekutuan, Malaysia

${ }^{2}$ Malaysian Research Institute on Ageing, Universiti Putra Malaysia, UPM, 43400 Serdang, Selangor, Malaysia

Full list of author information is available at the end of the article
}

of falling fertility and mortality rate, coupled with improvements in health system and therefore has brought about more people surviving into old age. Average life expectancy at birth of Malaysians has also increased for the past decades from 63.6 years in 1970 to 75.2 years in 2018 [2].

Increase in the proportion of the aged group means an increase in the prevalence of ill health and disabilities. Older people are associated with multiple acute and chronic diseases, greater medications usage as well as physiological changes of the ageing body systems $[3,4]$. In addition to that, impaired nutritional state has also

(c) The Author(s). 2019 Open Access This article is distributed under the terms of the Creative Commons Attribution 4.0 International License (http://creativecommons.org/licenses/by/4.0/), which permits unrestricted use, distribution, and reproduction in any medium, provided you give appropriate credit to the original author(s) and the source, provide a link to the Creative Commons license, and indicate if changes were made. The Creative Commons Public Domain Dedication waiver (http://creativecommons.org/publicdomain/zero/1.0/) applies to the data made available in this article, unless otherwise stated. 
become a significant problem among elderly worldwide $[5,6]$. In Malaysia, findings from the recent National Health and Morbidity Survey, NHMS, in 2015 showed that approximately $52.35 \%$ of older adults aged 60 years and above were overweight and obese [7].

Existing evidence indicated that several factors may have influence on nutritional status and healthy eating habit among elderly in the community. Oral health, as one of the associated factors, plays an important role in nutritional intake of older people. Poor oral health may expose the group at risk to underweight [8] or obese [9]. Reduced number of teeth and posterior occluding teeth among this group also had shown to affect their chewing ability leading to altered food choices and compromised nutritional status [10]. In addition to the clinical indicators, the impact of poor oral health on dimensions of quality of life also has been more pronounced among older people. Compromised dentition can lead to functional limitation (trouble biting and chewing food), psychological impacts (uncomfortable eating in front of others), pain and discomfort (discomfort when eating) and behavioural impacts (limit kinds or amount of foods) [11].

In recent decades, researchers have included the subjective assessment of psychological and social impacts as part of the analysis of oral health and nutritional status. Therefore, the oral health-related quality of life (OHRQoL) instruments can complement the objective clinical measurements and be used as a predictor of malnutrition in the aged population [12]. The Geriatric Oral Health Assessment Index, GOHAI, is one of the OHRQoL measurements that has been widely used in studies on self-perception of oral health among older population [13]. The internal consistency and validity of GOHAI have been shown to be satisfactory in several languages like Arabic, Japanese and Malay studies [14-16]. Several researchers have also used GOHAI when assessing the association between the impacts of oral conditions to nutritional status, as each of the GOHAI dimension focus on problems related to diet and nutrition like trouble biting or chewing food, discomfort when eating, uncomfortable eating in front of people and limit kinds or amounts of food $[12,17]$.

Body mass index, BMI, has been widely used for assessing the nutritional status of older adults in epidemiological studies $[18,19]$. It is considered as the most practical tool because of its simplicity and low cost [20]. Furthermore, BMI classification of body size like overweight and obese had contributed to increase in awareness of fatness problem, leading to more successful epidemiological and intervention research related to health outcomes [21].

As both oral health and nutritional status are strongly related to healthy behaviours, it is hypothesised that those who have poorer oral health may be less likely to be conscious about their diet. Therefore, the aim of this study was to assess the association between oral health-related quality of life and nutritional status among a group of community-dwelling older adults in the district of Kuala Pilah.

\section{Methods}

This cross-sectional study was conducted in the district of Kuala Pilah, Negeri Sembilan. The state of Negeri Sembilan is located at the west coast region of Peninsular Malaysia. Negeri Sembilan comprised of seven districts and is known to have a heterogeneous population in terms of ethnic groups and rural-urban distribution. Based from the 2010 Census of Malaysia, 19.1\% of the population in Negeri Sembilan are older adults aged 50 years and above [1]. The district of Kuala Pilah was chosen as it has the highest percentage of older adults more than 50 years of age $(25.8 \% ; n=16,499)$ among other districts in Negeri Sembilan.

Individuals aged 50 years and above, Malaysian, had been living in the selected areas for at least one year and could communicate clearly in Bahasa Malaysia were included in this study. Global studies on health and aging in several lower and upper-middle countries have also included aging adults aged 50 years and above as their respondents [22]. Those who were mentally ill and with other conditions that could affect the history taking and anthropometric measurements were excluded.

Based on a formula [23] used to calculate the adequate sample size in cross-sectional studies, $\mathrm{n}=\mathrm{z}^{2} \times \mathrm{P}(1-\mathrm{P}) / \mathrm{d}^{2}$, where $\mathrm{n}$ is the sample size, $\mathrm{z}$ is the level of confidence at $95 \%, \mathrm{P}$ is the estimated prevalence (51\% prevalence of unsatisfactory body mass index among older adults) [24], and $\mathrm{d}$ is precision of $5 \%$, the estimated sample size was 384 . With estimation of $15 \%$ non-response subjects, a sample size of 442 was required for this study.

Respondents were recruited using a two-stage cluster sampling. Two sub-districts of Kuala Pilah, Pilah and Johol, were included for sample selection and from each sub-district, 10 villages were randomly selected. Both the sub-districts have similar socio-economic background as well as the number of older adults residing in the areas. Through the head villages, all the older adults within the selected villages were invited to participate in a health and dental screening programme at their respected community halls. Prior to the interview and examination, respondents were briefed on the aim and conduct of the study. Those who agreed to participate and matched the selection criteria were included.

Approval to conduct the study was obtained from the Medical Research Ethics Committee, Faculty of Medicine and Health Sciences, Universiti Putra Malaysia (UPM/FPSK/PADS/T7-MJKEtikaPer/F01(IG_Mei(10)03) 
and all the respondents provided written informed consent. Data gathered included socio-demographic characteristics, oral health status, oral health-related quality of life and body mass index.

\section{Socio-demographic and oral health-related quality of life}

Data on socio-demographic and oral health-related quality of life were attained from the face-to-face questionnaire interview. Demographic variables involved items such as gender, age, ethnic group, educational level, living arrangement and medical conditions like hypertension, coronary heart disease, diabetes, asthma and arthritis. The 12-item Malay version of GOHAI was used to measure the oral health-related quality of life of the respondents in the past 3 months [16]. It consisted of three dimensions: physical function (4 items), psycho-social function (5 items) and, pain and discomfort (3 items). A five point Likert scale (always, often, sometimes, seldom and never) was used for measurement of the GOHAI index. The total GOHAI score was determined by summing the final score of each 12 items, ranged from 12 to 60 . Higher score indicates better oral health-related quality of life. The scales for three of the positively worded items in the GOHAI (able to swallow comfortably, pleased with appearance of teeth and able to eat any kind of food) were reversed so that a higher score can reflect better self-reported oral health. For the analysis in this study, a dichotomous category of GOHAI was used whereby older adults with a score of 57 and more were identified as having 'high perception' of oral health, while those who scored between 12 and 56 were identified as having 'low perception' [12, 17]. Oral examination was carried out to determine the number of teeth in the oral cavity (teeth present and total tooth loss). Only one examiner was involved with clinical oral examination and demonstrated high intra-examiner consistency (Kappa value of 0.96).

\section{Body mass index}

BMI was used to assess the nutritional status of the respondents. Respondents were measured for their standing height and weight, and readings were then used to calculate their BMI [weight $(\mathrm{kg}) /$ height $\left(\mathrm{m}^{2}\right)$ ]. The measurements were based on the Third National Health and Morbidity Survey format for anthropometrics measurement [25]. Weight was measured using Tanita 318 scale. The scale was checked for accuracy and calibrated prior to the start of the study. The respondents were asked to remove heavy items of clothing e.g. shoes and jackets, any heavy jewellery, keys and coins. After the scale was switched on and the zero reading displayed, the respondent was asked to stand on the scale. Weight was then recorded to the nearest $0.1 \mathrm{~kg}$. The respondent was required to step off the scale and the first reading from the scale's memory was cleared. The procedure was repeated and a second measurement made for an average reading. Height was measured using the SECA 206 portable body meter. The respondents were requested to stand straight, their feet together, arms loosely at their side, and with the head and back straight against the vertical surface of the wall. The respondent's head was positioned in the Frankfort plane horizontally and once the correct position was achieved, the head plate was lowered until it touched the top of the respondent's head. The measurement of height was recorded to the nearest $0.1 \mathrm{~cm}$. The procedures were repeated and a second measurement made for an average reading. The WHO 2000 classification [26] was used to classify BMI into underweight $\left(\leq 18.4 \mathrm{~kg} / \mathrm{m}^{2}\right)$, normal $\left(18.5-24.9 \mathrm{~kg} / \mathrm{m}^{2}\right)$, overweight $\left(25.0-29.9 \mathrm{~kg} / \mathrm{m}^{2}\right)$ and obese $\left(\geq 30.0 \mathrm{~kg} / \mathrm{m}^{2}\right)$. BMI was further classified into two groups, satisfactory and unsatisfactory. Those who were underweight, overweight and obese were categorized as having unsatisfactory BMI.

Statistical analysis was performed using SPSS version 22.0. Descriptive statistics were determined, such as means and standard deviation (SD) for continuous variables and frequency and percentages for categorical variables. Associations between categorical variables were assessed with the Chi-square test of independence. The significance level was set at $p<0.05$. A multiple logistic regression was constructed to evaluate the ability of GOHAI to predict unsatisfactory nutritional status among the older adults. BMI (satisfactory and unsatisfactory) was the dependent variable, while age group (50-69/70 \& above), self-reported chronic disease (yes/no), dental status (dentate/edentate) and total GOHAI score (high/low) were the independent variables included in the model. Confidence interval (CI) at $95 \%$ of the odds ratio (OR) and $p$-value of the association were obtained to make inferences to the study population.

\section{Results}

A total of 446 older adults participated in the study with $42.6 \%$ were men and $57.4 \%$ were women. The mean age was 63.2 years (SD 9.6). Majority (41.0\%) of the respondents were in the age group of 50-59 years while only $4.9 \%$ in the oldest age group ( $>80$ years old). In relation to formal educational level, $9.6 \%$ had never attended school, $84.8 \%$ were with primary and secondary level of education and only a small proportion (5.6\%) had tertiary education level. About $58.1 \%$ reported that they suffered from at least one medical condition.

The mean GOHAI score was 53.3 (SD 4.7). The mean score in those with satisfactory BMI was 53.9 (SD 4.9) and 52.9 (SD 4.5) in unsatisfactory BMI $(p<0.05)$. High 
proportion of the respondents (74.2\%) had poor perception (GOHAI <57) of oral health. Only $8.1 \%$ obtained a maximum score of 60 , indicating no impact from oral conditions.

The mean BMI was $26.3 \mathrm{~kg} / \mathrm{m}^{2}$ (SD 4.6). Majority of the respondents were overweight and obese, 40.4 and $19.9 \%$ respectively, $35.8 \%$ had normal body mass index and only $3.9 \%$ were underweight. Table 1 presents the demographic, oral health and nutritional characteristics of the older adults.

Table 2 summarizes the differences between satisfactory and unsatisfactory BMI by socio-demographic characteristics and dental status. Younger age group and with medical problems were significantly associated with having unsatisfactory BMI $(p<0.05)$. A significant association was also observed between total GOHAI score and BMI $(p<0.001)$.

Table 3 shows the differences between respondents with satisfactory and unsatisfactory BMI for the

Table 1 Demographic characteristics, dental status and BMI of the study population

\begin{tabular}{|c|c|}
\hline Items & $n(\%)$ \\
\hline \multicolumn{2}{|l|}{ Sex } \\
\hline Male & $190(42.6)$ \\
\hline Female & $256(57.4)$ \\
\hline Age group & $63.2(9.6)^{\mathrm{a}}$ \\
\hline $50-59$ & $183(41.0)$ \\
\hline $60-69$ & $133(29.8)$ \\
\hline 70-79 & $108(24.2)$ \\
\hline $80 \&$ above & $22(4.9)$ \\
\hline \multicolumn{2}{|l|}{ Education level } \\
\hline No formal education & $43(9.6)$ \\
\hline Primary \& secondary & $378(84.8)$ \\
\hline Tertiary & $25(5.6)$ \\
\hline \multicolumn{2}{|l|}{ Medical condition } \\
\hline Yes & $259(58.1)$ \\
\hline No & $187(41.9)$ \\
\hline \multicolumn{2}{|l|}{ Dental status } \\
\hline Dentate & $356(81.7)$ \\
\hline Edentate & $80(18.3)$ \\
\hline \multicolumn{2}{|l|}{ Total GOHAl score } \\
\hline High perception & $115(25.8)$ \\
\hline Low perception & $331(74.2)$ \\
\hline \multicolumn{2}{|l|}{ Body mass index (BMI) } \\
\hline Normal & $157(35.8)$ \\
\hline Underweight & $17(3.9)$ \\
\hline Overweight & $177(40.4)$ \\
\hline Obese & $87(19.9)$ \\
\hline
\end{tabular}

${ }^{\mathrm{a}}$ mean (SD)
Table 2 Association between demographic characteristics and dental status with BMI

\begin{tabular}{|c|c|c|c|}
\hline Variables & $\begin{array}{l}\text { Satisfactory BMl } \\
n(\%)\end{array}$ & $\begin{array}{l}\text { Unsatisfactory BMI } \\
n(\%)\end{array}$ & $p$-value \\
\hline \multicolumn{4}{|l|}{ Sex } \\
\hline Male & $68(43.3)$ & $117(41.6)$ & \multirow[t]{2}{*}{0.734} \\
\hline Female & $89(56.7)$ & $164(58.4)$ & \\
\hline \multicolumn{4}{|l|}{ Age Group } \\
\hline $50-59$ & $56(35.7)$ & $123(43.8)$ & \multirow[t]{4}{*}{$0.010^{*}$} \\
\hline $60-69$ & $43(27.4)$ & 89 (31.6) & \\
\hline $70-79$ & $45(28.6)$ & $62(22.1)$ & \\
\hline 80 \& above & $13(8.3)$ & $7(2.5)$ & \\
\hline \multicolumn{4}{|l|}{ Education level } \\
\hline No formal education & $16(10.2)$ & $27(9.6)$ & \multirow[t]{3}{*}{0.407} \\
\hline Primary \& secondary & $129(82.2)$ & $241(85.8)$ & \\
\hline Tertiary & $12(7.6)$ & $13(4.6)$ & \\
\hline \multicolumn{4}{|l|}{ Medical condition } \\
\hline Yes & $80(51.0)$ & $174(61.9)$ & \multirow[t]{2}{*}{0.026} \\
\hline No & 77 (49.0) & $107(38.1)$ & \\
\hline \multicolumn{4}{|l|}{ Dental status } \\
\hline Dentate & $122(78.2)$ & $228(83.8)$ & \multirow[t]{2}{*}{0.147} \\
\hline Edentate & $34(21.8)$ & $44(16.2)$ & \\
\hline \multicolumn{4}{|l|}{ GOHAl score } \\
\hline High perception & $56(35.7)$ & 55 (19.6) & \multirow[t]{2}{*}{$<0.001^{*}$} \\
\hline Low perception & $101(64.3)$ & $226(80.4)$ & \\
\hline
\end{tabular}

*Significant at $p$-level $<0.05$

percentage of responses for each of the GOHAI item. Compared to respondents who had satisfactory BMI, those with unsatisfactory BMI restricted more frequently the types of food they take and experienced more problems with biting or chewing $(p<0.01)$. Results in Table 3 also shows that respondents with unsatisfactory BMI were more frequently worried and self-conscious about their teeth, gums and dentures, used medications to relieve their pain and unable to eat any kinds of foods. Nevertheless, no significant differences were observed.

A multiple logistic regression was constructed to evaluate the ability of GOHAI to predict unsatisfactory nutritional status among the older adults. The Hosmer and Lemeshow goodness-of-fit test was used to assess whether the final model accurately fits the data used. After adjusting for age, medical condition and dental status, a significant association was found between total GOHAI score and BMI. Respondents with lower total GOHAI score (low perception of oral health) were more likely to experience unsatisfactory BMI (Adjusted OR $=2.31 ; 95 \%$ CI 1.46, 3.64; $p<0.01$ ) (Table 4). 
Table 3 Percentage of responses of to each item of GOHAl based on BMI

\begin{tabular}{|c|c|c|c|c|c|c|c|}
\hline \multirow[t]{2}{*}{ GOHAl items } & \multicolumn{3}{|c|}{ Satisfactory BMI } & \multicolumn{3}{|c|}{ Unsatisfactory BMI } & \multirow[t]{2}{*}{$p$} \\
\hline & 1 & 2 & 3 & 1 & 2 & 3 & \\
\hline \multicolumn{8}{|l|}{ Physical function } \\
\hline Limit the kinds of food & 14.0 & 40.8 & 45.2 & 14.2 & 56.2 & 29.5 & $0.003^{*}$ \\
\hline Trouble biting or chewing & 15.9 & 41.4 & 42.7 & 15.7 & 56.5 & 27.8 & $0.003^{*}$ \\
\hline Able to swallow comfortably & 94.9 & 5.1 & 0 & 95.7 & 4.3 & 0 & 0.812 \\
\hline Unable to speak clearly & 0.6 & 10.8 & 88.6 & 1.1 & 8.9 & 90.0 & 0.733 \\
\hline \multicolumn{8}{|l|}{ Psychosocial } \\
\hline Limit contacts with people & 0.6 & 10.8 & 88.6 & 0.4 & 8.9 & 90.7 & 0.733 \\
\hline Pleased with appearance of teeth & 100.0 & 0 & 0 & 99.6 & 0.4 & 0 & 0.642 \\
\hline Worried about teeth, gums or denture & 0 & 15.3 & 84.7 & 2.1 & 12.8 & 85.1 & 0.149 \\
\hline Self-conscious of teeth, gums or denture & 0 & 13.4 & 86.6 & 0.7 & 12.1 & 87.2 & 0.535 \\
\hline Uncomfortable eating in front of others & 0.6 & 11.5 & 87.9 & 0.4 & 9.3 & 90.3 & 0.692 \\
\hline \multicolumn{8}{|l|}{ Pain/Discomfort } \\
\hline Able to eat any kind of food & 73.2 & 26.1 & 0.6 & 67.3 & 32.0 & 0.7 & 0.426 \\
\hline Use of medication to relieve pain & 1.3 & 15.9 & 82.8 & 2.8 & 17.1 & 80.1 & 0.531 \\
\hline Sensitive to hot, cold or sweet foods & 7.0 & 26.8 & 66.2 & 4.6 & 24.6 & 70.8 & 0.463 \\
\hline
\end{tabular}

1-Always \& often 2-Sometimes \& seldom 3-Never

*significant at $p$-level $<0.05$

\section{Discussion}

In this study, older adults with poor perception of their oral health had unsatisfactory BMI. Consistent results were also observed in other studies that evaluated the association between OHRQoL and nutritional status in older population $[8,17]$. Respondents with poor GOHAI score were shown to be at risk of nutritional deficiencies. However, most of these studies used Mini-Nutritional Assessment (MNA) for measuring nutritional status,

Table 4 Multiple logistic regression analysis for the association between total GOHAl score and unsatisfactory BMl

\begin{tabular}{|c|c|c|c|}
\hline Variables & Adjusted Odd Ratio $^{a}$ & $95 \%$ of $\mathrm{Cl}$ for $\mathrm{OR}$ & $p$ value \\
\hline \multicolumn{3}{|l|}{ Age group ${ }^{b}$} & \multirow[t]{3}{*}{$0.011^{*}$} \\
\hline $50-69$ & 1.84 & $1.15,2.94$ & \\
\hline 70 \& above & 1.0 & - & \\
\hline \multicolumn{3}{|c|}{ Medical condition ${ }^{b}$} & \multirow[t]{3}{*}{$0.016^{*}$} \\
\hline Yes & 1.67 & $1.10,2.52$ & \\
\hline No & 1.0 & - & \\
\hline \multicolumn{3}{|l|}{ Dentate status ${ }^{b}$} & \multirow[t]{3}{*}{0.43} \\
\hline Dentate & 1.0 & - & \\
\hline Edentate & 0.80 & $0.47,1.39$ & \\
\hline \multicolumn{4}{|c|}{ Perception of oral health (GOHAl score) } \\
\hline High & 1.0 & - & \multirow[t]{2}{*}{$<0.001^{*}$} \\
\hline Low & 2.31 & $1.46,3.64$ & \\
\hline
\end{tabular}

${ }^{\mathrm{a}}$ The multiple logistic regression model is reasonably fit with HosmerLemeshow goodness of fit. $\left(X^{2}(8)=10.968 ; p=0.204\right)$, area under $\mathrm{ROC}=0.67$ ${ }^{\mathrm{b}}$ There is no significant interaction between age group, medical condition and dentate status (Controlled variables) thus comparison can only be made on the risk of nutritional deficit and not the actual BMI score.

Association between impacts of oral health on the quality of life with nutritional status have been established in several studies $[8,27]$. As most of the impacts were related to eating and chewing, impaired nutrients intake could be evident among the elderly group. GOHAI evaluates the impact of oral conditions on the dimensions of oral health-related quality of life. The index focuses mainly on mastication-related problems in all dimensions - limit on types and amount of food, difficulties with biting or chewing food, discomfort when eating or swallowing and feeling uncomfortable eating in front of others. A high prevalence of these problems was reported among all the GOHAI items [14, 16, 28] and therefore would present a strong association between the OHRQoL measure and nutritional status. Similarly, in the present study, older adults with unsatisfactory BMI had shown significant difference in relation to the frequency of restriction of food and chewing problems. In Malaysia, rice, fish, green vegetables, bread and local kuih were among the common food consumed in a day [29]. As most of older adults have compromised dentition, avoidance of these food due to limited number of teeth is more likely to occur.

Cousson et al in 2012 examined two groups of elderly, fully dentate and complete denture wearers, to identify the factors associated with risk of malnutrition. Findings revealed that fully dentate elderly individuals have better GOHAI score, indicating less impact of oral conditions on their oral health-related quality of life. Elderly with least risk of malnutrition were those fully dentate, living 
in a couple and have high mean GOHAI score [30]. Similar findings were highlighted in an Australian study in which older adults with better perception of oral health (higher GOHAI score) were among those at least risk of malnutrition (lower MNA score) [31]. As both oral health and nutritional status are strongly related to healthy behaviours, these findings may also suggest that those who have poorer oral health may be less likely to be conscious about their diet. However, a causal relationship between malnutrition and OHRQoL could not be explained as both studies were cross sectional in design, thus future longitudinal research are required to address the association.

Clinical measurements like reduced number of teeth and occluding teeth, dental caries and periodontal disease have been commonly linked to nutritional deficit [32]. Decline in the oral health characteristics could lead to negative self-perception of oral health as defined by the GOHAI [33]. Beside the above mentioned clinical parameters, it can also be suggested that poor self-perception on oral health was one of the variables associated with nutritional deficiencies. Therefore, it is evident that OHRQoL instruments can complement the objective clinical measurements and be used as a predictor of malnutrition especially in the aged population.

Contrarily, no association was found between OHRQoL measurements and nutritional status among older adults in some studies $[34,35]$. This may be explained by the various factors affecting food choices and intakes among elderly, like general health, socioeconomic factors, taste and control over food preparation [36]. There may also be lack of knowledge on nutritive value of foods consumed among the older individuals, putting them still at risk of malnutrition regardless of their oral perceptions. Furthermore, the sample size in the previous study was small and therefore results might not be parallel to the present study.

Findings from this study also highlighted that majority of the respondents were overweight and obese (40.4 and $19.9 \%$ respectively). One of the possible reasons may be due to the level of education among respondents in which $55.1 \%$ of them have only primary or without formal education. Level of education has influence on elder's nutrition knowledge and practice, giving impact to their nutritional health [37]. It was reported that 73\% of Malaysians elderly have poor nutrition knowledge and this was significantly correlated with educational status [38]. Similarly, poor oral health status was associated with low education level and may have positive impact on general and oral health-related quality of life [39].

In Malaysia, the National Oral Health Survey of Adults, NOHSA (2010) has reported the impacts of oral conditions on the oral health-related quality of life of the population studied. More than one quarter of the respondents (29.3\%) had experienced at least one or more impact and the proportion increased with age [40]. Similar to the earlier NOHSA data in $2000,54.3 \%$ of elderly aged 75 years and above complained of oral functional limitations. Among those with oral functional limitations, majority (19.6\%) reported problems with chewing hard foods. Of those who reported problems with chewing, edentulous elderly without dentures had the most impact (85.7\%) compared to edentate with dentures and dentate groups [41]. These unfavourable results for chewing-related problems should alert the dental practitioners of the possibility of nutritional problems especially in the aged populations. Despite of the high impact of oral conditions on OHRQoL, utilization of dental care service by the elderly remains low [41]. Similar report showed that utilization of oral care services among older people in Malaysia was the lowest compared to younger population. Further studies focusing on ways to eliminate barriers and encourage uptake of dental services need to be developed.

The study also indicated that older adults with unsatisfactory BMI significantly decreased with advancing age. This pattern is consistent with the local data of NHMS 2015 study in which the reason could be due to the fact that older individuals with unsatisfactory BMI, for example obesity, had died earlier because of chronic diseases related to the condition like cardiovascular diseases, thus leaving the non- obese individuals with a higher survival rate in the older age group [42].

Despite the associations observed, one of the limitation of this study was it could not establish a causal relation between OHRQoL and nutritional status as its cross-sectional design. Longitudinal studies may be needed to further explore the relationship. As cluster sampling technique was applied in the study, sampling error could also occur and lead to over- or under-represented in the final conclusion. Nevertheless, both selected sub-districts have similar socio-economic background as well as the number of respondents. Another limitation was the use of self-reported tools to measure the oral health-related quality of life among the respondents. The GOHAI has potential bias as they rely on respondents' memory and ability to identify the oral health impacts [43]. Furthermore, older people are associated with high prevalence of hearing and memory problems which may lead to additional sources of bias. Nevertheless, highly trained interviewers were used to conduct such procedures to improve reliability of the study. Moreover, it can yield relevant information on the self-perceived oral impacts among older population especially in relation to masticatory ability. To date, local data on self-perception of oral health among the older age group is very scant, so therefore it could add to the limited literature on oral health and nutrition at the community level. 


\section{Conclusion}

In conclusion, this study suggested that older adults with poor perception of oral health were more likely to have unsatisfactory BMI. The application of oral health-related quality of life instruments together with objective clinical measurements need to be emphasized as it could be utilised as oral health predictors that might lead to impaired nutrition in the older population.

\section{Abbreviations}

BMI: Body mass index; GOHAl: Geriatric Oral Health Assessment Index; NHMS: National Health and Morbidity Survey; NOHSA: National Oral Health Survey of Adults; OHRQoL: Oral health-related quality of life

\section{Acknowledgements}

We thank all heads of villages involved in the district of Kuala Pilah for their assistance and also to all residents who participated in the study.

\section{Funding}

The authors acknowledged the financial assistance for publication received from the Research University Grant awarded by the Ministry of Health to the National University of Malaysia specifically for the Consortium of B40 Research (CB40R) under the auspice of B40 Grand Challenges (IDE 2018-01).

\section{Availability of data and materials}

The datasets used during the study are available from the corresponding author on reasonable request.

\section{About this supplement}

This article has been published as part of BMC Public Health Volume 19 Supplement 4, 2019: Health and Nutritional Issues Among Low Income Population in Malaysia. The full contents of the supplement are available online at https://bmcpublichealth.biomedcentral.com/articles/supplements/ volume-19-supplement-4.

\section{Authors' contributions}

TIR, YMC, RAK and TAAH contributed equally and have read and approved the final manuscript.

\section{Ethics approval and consent to participate}

This study was approved by the Medical Research Ethics Committee, Faculty of Medicine and Health Sciences, Universiti Putra Malaysia (UPM/FPSK/PADS/ T7-MJKEtikaPer/F01(IG_Mei(10)03). Written consent were obtained from all the respondents.

\section{Consent for publication}

Not applicable.

\section{Competing interests}

The authors declare that they have no competing interests.

\section{Publisher's Note}

Springer Nature remains neutral with regard to jurisdictional claims in published maps and institutional affiliations.

\section{Author details}

'Department of Dental Public Health, Faculty of Dentistry, Universiti Kebangsaan Malaysia, Jalan Raja Muda Abdul Aziz, 50300 Kuala Lumpur, Wilayah Persekutuan, Malaysia. ${ }^{2}$ Malaysian Research Institute on Ageing, Universiti Putra Malaysia, UPM, 43400 Serdang, Selangor, Malaysia. ${ }^{3}$ Department of Nutrition and Dietetics, Faculty of Medicine and Health Sciences, Universiti Putra Malaysia, UPM, 43400 Serdang, Selangor, Malaysia. ${ }^{4}$ Faculty of Dentistry, Lincoln University College, No 2, Jalan Stadium, SS 7/15 Kelana Jaya, 47301 Petaling Jaya, Selangor, Malaysia.
Published: 13 June 2019

\section{References}

1. Population and housing census of Malaysia: Population distribution and basic demographic characteristics 2010. Department of Statistics Malaysia. 2011. Kuala Lumpur.

2. Current population estimates 2017. Department of Statistics Malaysia. 2018. Kuala Lumpur.

3. Husin NM, Shahar S, Din NC, Singh DKA, Chin AV, Razali R, et al. Incidence and predictors of multimorbidity among a multi-ethnic population in Malaysia: a community-based longitudinal study. Aging Clin Exp Res. 2019;31:215

4. Lim LM, McStea M, Chung WW, Azmi NN, Aziz SAA, Alwi S, et al. Prevalence, risk factors and health outcomes associated with polypharmacy among urban community-dwelling older adults in multi-ethnic Malaysia. PLoS One. 2017;12:3

5. Mohd Fakhruddin NNIN, Shahar S, Aziz NAA, Yahya HM, Rajikan R. Which aging group prone to have inadequate nutrient intake? Sains Malaysiana. 2016;45:1381-91.

6. Mitri R, Boulos C, Adib SM. Determinants of the nutritional status of older adults in urban Lebanon. Geriatr Gerontol Int. 2017;17:424-32.

7. Chan YY, Lim KK, Lim KH, Teh CH, Kee CC, Cheong SM, et al. Physical activity and overweight / obesity among Malaysian adults: findings from the 2015 National Health and morbidity survey (NHMS). BMC Public Health. 2017;17:733

8. El Osta N, Hennequin M, Tubert-Jeannin S, Naaman NB, El Osta L, Geahchan $\mathrm{N}$. The pertinence of oral health indicators in nutritional studies in the elderly. Clin Nutr. 2014;33:316-21.

9. Peruchi CT, Poli-Frederico RC, Cardelli AA, Fracasso MD, Bispo CG, NevesSouza RD, et al. Association between oral health status and central obesity among Brazilian independent-living elderly. Braz Oral Res. 2016;30:1.

10. Rosli TI, Chan YM, Kadir RA, Hamid TAH. Association between tooth loss and body mass index among older adults in Kuala Pilah, Negeri Sembilan. Malaysian J Health Sci. 2018;16:81-6.

11. Hew PF, Lee JE, Tew IM, Ahmad R, Aziz AFA, Sais SM, et al. Impact of tooth loss and preferences for tooth replacement among clinic attendees at a public university. J Dent Indonesia. 2018;25:108-13.

12. Gil-Montoya JA, Subira C, Ramon JM, Gonzalez-Moles MA. Oral healthrelated quality of life and nutritional status. J Public Health Dent. 2008;68:88-93.

13. Rebelo MA, Cardoso EM, Robinson PG, Vettore MV. Demographics, social position, dental status and oral health-related quality of life in communitydwelling older adults. Qual Life Res. 2016;25:1735-42.

14. Atieh MA. Arabic version of the geriatric Oral health assessment index. Gerodontology. 2008;25:34-41.

15. Naito M, Suzukamo Y, Nakayama T, Hamajima N, Fukuhara S. Linguistic adaptation and validation of the General Oral health assessment index (GOHAl) in an elderly Japanese population. J Public Health Dent. 2006;66:273-5.

16. Othman WN, Muttalib KA, Bakri R, Doss JG, Jaafar N, Salleh NC, et al. Validation of the geriatric oral health assessment index (GOHAl) in the Malay language. J Public Health Dent. 2006;66:199-204.

17. Kshetrimayum N, Reddy CV, Siddhana S, Manjunath M, Rudraswamy S, Sulavai S. Oral health-related quality of life and nutritional status of institutionalized elderly population aged 60 years and above in Mysore City. India Gerontol. 2013;30:119-25.

18. Kim YS, Kim JH. Body mass index and oral health status in Korean adults: the fifth Korea National Health and nutrition examination survey. Int J Dent Hyg. 2017:15:172-8.

19. Koodaryan R, Hafezeqoran A, Nourizadeh A, Rahimi AO, Ahmadian M. The relationship between dental status, body mass index and nutrient intake. Adv Biosci Clin Med. 2014;2:24

20. Barao K, Forones NM. Body mass index: different nutritional status according to WHO, OPAS and Lipschitz classifications in gastrointestinal cancer patients. Arg Gastroenterol. 2012;49:169-71.

21. WHO Expert Consultation. Appropriate body mass index for Asian populations and its implications for policy and intervention strategies. Lancet. 2004:363:157-63.

22. Chatterji S. World Health Organization's (WHO) study on global ageing and adult health (SAGE). BMC Proc. 2013;7:S4.

23. Fleiss JL. Statistical methods for rates and proportions. New York: Wiley; 1981. 
24. Shahar S, Ibrahim Z, Fatah AR, Rahman SA, Yusoff NA, Arshad F, et al. A multidimensional assessment of nutritional and health status of rural elderly Malays. Asia Pac J Clin Nutr. 2007;16:346-53.

25. Institute of Public Health. Technical Manual for Anthropometric Measurement. The third National Health and morbidity survey 2006. Kuala Lumpur, Malaysia: Ministry of Health; 2006.

26. World Health Organization. Obesity: preventing and managing the global epidemic. Report of a WHO consultation. In: WHO technical report series 894. Geneva: World Health Organization; 2000.

27. Pillai RS, Mathur VP, Jain V, Shah N, Kalra S, Kumar P, et al. Association between dental prosthesis need, nutritional status and quality of life of elderly subjects. Qual Life Res. 2015;24:2863-71.

28. Fuentes-Garcia A, Lera L, Sanchez H, Albala C. Oral health-related quality of life of older people from three south American cities. Gerodontology. 2013;30:67-75.

29. Norimah AK, Safiah M, Jamal K, Haslinda S, Zuhaida H, Rohida S, et al. Food consumption pattern: findings from the Malaysian adult nutrition survey (MANS). Mal J Nutr. 2008;14:25-39.

30. Cousson PY, Bessadet M, Nicolas E, Veyrune JL, Lesourd B, Lassauzay C. Nutritional status, dietary intake and oral quality of life in elderly complete denture wearers. Gerodontology. 2012;29:e685-92.

31. Hugo C, Cockburn N, Ford P, March S, Isenring E. Poor nutritional status is associated with worse oral health and poorer quality of life in aged care residents. Jour Nursing Home Res. 2016;2:118-22.

32. Nascimento GG, Leite FRM, Conceicao DA, Ferrua CP, Singh A, Demarco FF. Is there a relationship between obesity and tooth loss and edentulism? A systematic review and meta-analysis. Obes Rev. 2016;17:587-98.

33. Rekhi A, Marya CM, Oberoi SS, Nagpal R, Dhingra C, Kataria S. Periodontal status and oral health-related quality of life in elderly residents of aged care homes in Delhi. Geriatr Gerontol Int. 2015;16:474-80.

34. Allen PF. Association between diet, social resources and oral health related quality of life in edentulous patients. J Oral Rehabil. 2005;32:623-8.

35. Daly RM, Elsner RJF, Allen PF, Burke FM. Associations between self-reported dental status and diet. J Oral Rehabil. 2003;30:964-70.

36. Kamphuis $\mathrm{CB}$, de Bekker-Grob EW, van Lenthe FJ. Factors affecting food choices of older adults from high and low socioeconomic groups: a discrete choice experiment. Am J Clin Nutr. 2015:101:768-74.

37. Han Y, Li S, Zheng Y. Predictors of nutritional status among communitydwelling older adults in Wuhan. China Public Health Nutr. 2009;12:1189-96.

38. Karim NA, Safii NS, Yusof SM, Noor NM, Ahmad Z, Tee ES. Nutrition knowledge among Malaysian elderly. Malaysian J Health Sci. 2008;6:43-54

39. Tiwari T, Scarbro S, Bryant LL, Puma J. Factors associated with tooth loss in older adults in rural Colorado. J Community Health. 2016;41:476-81.

40. Oral Health Division, Ministry of Health Malaysia. National oral health survey of adults 2010 (NOHSA 2010). 2013. Putrajaya.

41. Oral Health Division, Ministry of Health Malaysia. National oral health survey of adults 2000 (NOHSA 2000). 2004. Kuala Lumpur.

42. Institute for Public Health (IPH) 2015. National Health and morbidity survey 2015 (NHMS 2015). Vol. II: Non-Communicable Diseases, Risk Factors \& Other Health Problems; 2015.

43. Moynihan P, Thomason M, Walls A, Gray-Donald K, Morais JA, Ghanem H, et al. Researching the impact of oral health on diet and nutritional status: methodological issues. J Dent. 2009;37:237-49.

Ready to submit your research? Choose BMC and benefit from:

- fast, convenient online submission

- thorough peer review by experienced researchers in your field

- rapid publication on acceptance

- support for research data, including large and complex data types

- gold Open Access which fosters wider collaboration and increased citations

- maximum visibility for your research: over $100 \mathrm{M}$ website views per year

At $\mathrm{BMC}$, research is always in progress.

Learn more biomedcentral.com/submissions 